\title{
REFlEXões DOCENTES SOBRE PRÁTICAS DE ENSINO DA Disciplina DE GEOGRAFIA EM UMA ESCOLA PÚBLICA DE MATO GRosSo
}

\author{
TEACHING REFLECTIONS ON EDUCATIONAL PRACTICES OF GEOGRAPHY \\ IN A PUBLIC SCHOOL OF MATO GROSSO
}

DOI: 10.23926/RPD.2526-2149.2020.v5.n2.p1374-1394.id777

\section{Renata Maria da Silva Mestra em Geografia (UNEMAT) \\ Professora da Educação \\ Básica (SEDUC/MT) \\ renatamaria.enzo@gmail.co \\ $\underline{m}$}

\section{Aumeri Carlos Bampi \\ Doutor em Filosofia e \\ Ciências da Educação \\ (USC/Espanha) \\ Docente da Pós-graduação \\ em Ciências Ambientais \\ (PPGCA/UNEMAT) e da \\ Geografia \\ (PPGGEO/UNEMAT) \\ profaumericarlosbampi@gm ail.com}

\section{Judite de Azevedo do Carmo}

Doutora em Geografia (UNESP/Rio Claro)

Docente da Pós-Graduação

em Geografia

(UNEMAT/Cáceres) e do

Curso de Graduação em

Geografia (UNEMAT)

judite.carmo@unemat.br
Resumo: O estudo analisa, a partir das reflexões docentes, as práticas de ensino da disciplina de Geografia em uma escola pública de Mato Grosso. A pesquisa, de cunho qualitativo, apoiou-se em revisão bibliográfica e na realização de entrevistas com professores. Os resultados evidenciam que, frente à ausência de materiais e equipamentos, de recursos financeiros, de qualificação stricto sensu e de formação continuada e, ainda, desinteresse dos alunos a essa área de saber, a docência é um desafio. Para a superação propõem maior investimento. Apontam que o livro didático é importante instrumento de ensino, mas é necessário aprofundar com o uso de outros materiais e metodologias diversificadas. Consideram que trabalhar a realidade local é essencial para o aluno compreender a Geografia como instrumento de interpretação crítica do seu mundo, mas expressam que há ausência de materiais bibliográficos e não há destinação de recursos a atividades fundamentais como visitações e aulas de campo.

Palavras-chave: Ensino de Geografia. Docência. Geografia Local. Práticas de Ensino.

\begin{abstract}
This study analyses, from teaching reflections, the educational practices of Geography in a public school of Mato Grosso. The research, of qualitative approach, was supported by a literature review and interviews with teachers. The results evince that, due to the absense of materials and equipments; of financial resources; of stricto sensu qualification and continuing education, and also because of lack of interest on the part of students regarding the field of knowledge, the teaching profession is a challenge. To overcome these issues, the teachers suggest more investiments. They point out that the textbook is important as a teaching tool, but that it is necessary to use also other materials and methodologies. They consider that to work on the local reality is essential for the student to perceive Geography as an instrument of critical analysis of their world, but they express that there is absense of bibliographic materials and allocation of resources to do basic activities such as school trips and outdoor classes.
\end{abstract}

Keywords: Geography Teaching. Teaching Profession. Local Geography. Educational Practices. 


\section{INTRODUÇÃO}

O ensino de Geografia integra o currículo da educação básica brasileira desde o ano de 1837. Desde então, passou por mudanças em suas práticas metodológicas com o intuito de atender a interpretação das transformações evidenciadas na sociedade. De um ensino pautado na memorização dos fenômenos geográficos, transformou-se em um ensino que pretende a compreensão dinâmica das relações sociais, de trabalho, econômicas, políticas, ambientais e tecnológicas, bem como dos processos que influenciam a transformação do espaço geográfico.

Essas transformações citadas são constantes nas sociedades contemporâneas, também o são as mudanças educacionais, em especial da função da escola, do papel do professor, dos currículos, do uso de instrumentos tecnológicos e de mediação do ensino. No processo educativo não foi diferente em relação ao ensino de Geografia, visto que a contemporaneidade instiga duas questões: um currículo sintonizado com as dinâmicas sociais, econômicas, políticas e ambientais, e o uso das inovações e avanços tecnológicos na educação, evidentes em um mundo cada vez mais globalizado, interconectado e dependente. Contudo, ainda é possível encontrar no ensino de Geografia algum vestígio de metodologias tradicionais, que pouco contribuem para que o estudante seja o sujeito de seu conhecimento e possa compreender e transformar a realidade em que vive. Em outros termos, não se descarta a importância da memorização, no entanto, é necessário frisar que sem reflexão e interpretação, possivelmente, corre-se o risco de um conhecimento estático, passível de equívocos.

Assim sendo, estudos e reflexões sobre a Geografia escolar são essenciais, especialmente no momento atual, tendo em vista que a sociedade se torna cada vez mais dinâmica e globalizada com relações altamente complexas. Em resposta às mudanças que vêm ocorrendo, tanto no espaço nacional quanto no global, a ciência geográfica e o ensino de Geografia necessitam constantemente refletir e rever seus conceitos, conteúdos e metodologias, a fim de acompanhar as transformações nas/das sociedades contemporâneas.

No que se refere à reflexão sobre o ensino, a investigação da realidade se torna premente para tal tarefa. Deste modo, com a finalidade de aprofundamento, foi realizada uma pesquisa em uma escola pública estadual, localizada em Vera, município mato-grossense pertencente à região da Amazônia Legal, razão pela qual é importante tratar do contexto, pois o território do município sofreu grandes transformações socioambientais a partir do Programa de Integração Nacional (PIN) desenvolvido na década de 1970, em que recursos financeiros e a força de trabalho (camponeses e outros trabalhadores) foram direcionados dentro do projeto de 
expansão capitalista ao Centro-Oeste e Amazônia à fronteira em busca de terra e trabalho (DA SILVA; BAMPI, 2020).

No município, o processo de transformações espaciais teve início com a colonização em 1971, a partir da inserção de migrantes sulistas que iniciaram a abertura de áreas para a agricultura em precárias condições de saúde, de alimentação, de mobilidade e de comunicação, com escassa infraestrutura (DA SILVA, BAMPI, 2020).

Na sequência, foram implantadas outras atividades, como a exploração madeireira, que em razão do insucesso agrícola inicial, tornou-se uma atividade cada vez mais forte. No entanto, sem planejamento, a exploração depredatória da madeira (riqueza econômica nas décadas de 1980 e 1990) entrou em declínio. Na década de 2000 adentrou a fase do agronegócio ou agricultura comercial de larga escala, influenciada pelo processo de expansão já ocorrido em municípios do entorno, o que trouxe intensa adulteração do bioma pela supressão da floresta para o cultivo de soja em extensos latifúndios (KOHLER; BAMPI; SILVA, 2018).

Por essa razão, o ensino de Geografia figura como uma ferramenta imprescindível ao correlacionar as rugosidades locais ao processo de ensino-aprendizagem. Diante dessa conjuntura, o objetivo central deste artigo é analisar a partir de reflexões docentes, as práticas de ensino da disciplina de Geografia em uma escola pública de Mato Grosso. A pesquisa encontra justificativa na possibilidade de contribuir com as discussões sobre o ensino de Geografia na Educação Básica, com o intuito de colaborar com a aprendizagem significativa. A prática de ensino da Geografia escolar evoluiu significativamente desde que se tornou parte do currículo escolar brasileiro; entretanto, precisa sempre ser estudada e aperfeiçoada conferir sentido e possibilitar compreensão do espaço vivido - esforço proposto por este estudo.

\section{O ENSINO DE GEOGRAFIA NA EDUCAÇÃo BÁSICA: ELEMENTOS TEÓRICOS}

O ensino de saberes geográficos, no período colonial, já ocorria em algumas instituições comandadas pelos jesuítas. A disciplina era ministrada de forma diluída em textos literários. Em 1810, fez parte do programa do curso de formação de engenheiros geógrafos militares da Academia Real Militar, no Rio de Janeiro. Em 1831, os conhecimentos geográficos eram prérequisitos nos Cursos Superiores de Direito (MELO; VLACH; SAMPAIO, 2006).

Como componente curricular, a disciplina de Geografia passou a ser obrigatória nas escolas brasileiras em 1837, por meio de um Decreto expedido pela Regência Interina, incluindo-a ao corpo de disciplinas obrigatórias do Imperial Colégio Pedro II, na cidade do Rio de Janeiro. Em virtude de essa instituição ser, à época, referência nacional, a medida foi adotada 
também nas demais instituições do país (ROCHA, 1996). A priori, o ensino de Geografia tinha base na memorização de fatos e fenômenos (Geografia Tradicional/Clássica).

No século XX, passou por alterações, tendo em vista a inserção de discussão com base em conteúdos explicativos e não apenas descritivos (Geografia Teorética-Quantitativa); todavia, sem erradicar as metodologias de ensino da Geografia tradicional (ROCHA, 1996).

Na década de 1960, houve diversas discussões sobre o papel do ensino, sobre a inserção de assuntos do cotidiano e reflexões sobre a vida e o mundo, principalmente nas aulas de Geografia. Essas proposições, no entanto, foram interrompidas com o Golpe Militar de 1964 e só voltaram a ganhar força com o início do processo de redemocratização, no final da década de 1970. Neste período, surgiu uma nova perspectiva da Geografia, mais voltada à realidade da sociedade brasileira, ou seja, a Geografia Crítica (MELO; VLACH; SAMPAIO, 2006).

Durante o período ditatorial no Brasil, as disciplinas de História e Geografia foram unificadas, formando, portanto, a disciplina de Estudos Sociais. Assim, a ciência geográfica foi trabalhada com viés ideológico de uma sociedade estática e sem contradições, dedicada a estudar aspectos a partir de uma visão positivista-funcionalista. Desse modo, pouco contribuiu para a compreensão do espaço geográfico e das transformações da sociedade brasileira e do território. Com o processo de redemocratização do país, a partir de final da década de 1980, principalmente no final do século XX, a Geografia tomou novos rumos, renovando-se e proporcionando reformulações em seus fundamentos políticos, ideológicos e epistemológicos (FERNANDES, 2012).

No final da década de 1970, surgiu forte interesse científico acerca da Geografia Crítica, sobre sua função, objetivo, entre outros assuntos que envolviam a disciplina. Os acontecimentos dos anos 1980 são frutos das lutas da década anterior, dos estudos dos professores, das Associações de Geógrafos e demais profissionais interessados no reconhecimento do valor do ensino de Geografia. Foi um período de importância para o país, que buscava reaver os direitos civis e a redemocratização após o longo período da ditadura militar (MATO GROSSO, 2018).

Com base na Geografia Crítica, o ensino começou a priorizar a análise das relações sociais, do mundo do trabalho, a produção e a transformação do espaço geográfico e a expansão do capital. A Geografia começou a ser compreendida não mais como ciência que somente descreve os fatos e fenômenos, mas também como ativa e contribuinte para a transformação das realidades (FERNANDES, 2012).

De acordo com Oliveira (1989), no contexto do final da década de 1980, entraram em embate duas vertentes do ensino de Geografia: a Geografia Neutra e a Geografia Crítica. A 
primeira buscava o enfoque nos recursos físicos; a segunda, buscou instrumentalizar e potencializar os estudantes para seu desenvolvimento e sua formação cidadã a partir da realidade social encontrada. A Geografia Crítica apostava que o ensino, direcionado à grande massa de trabalhadores, traria a possibilidade de atuar para a construção de um futuro melhor, com justiça e dignidade, pois, conforme fossem aprendendo a pensar e a agir criticamente, seriam construtores - e não espectadores - de suas vidas futuras.

Celeri, Lima e Oliveira (2017) evidenciam que a Geografia Crítica é de grande importância para a compreensão da sociedade contemporânea, pois, além da leitura e interpretação crítica do espaço, preocupa-se principalmente com a transformação da realidade, com a formação de cidadãos ativos, conscientes e participativos. Desse modo, os estudantes cultivam autonomia interpretativa, "como o senso crítico, a criatividade, o raciocínio lógico, a capacidade de interpretação de mapas e paisagens e ter atitudes democráticas e racionais perante os outros e o meio ambiente" (CELERI; LIMA; OLIVEIRA, 2017, p. 7).

Em concomitância com a Geografia Crítica, a partir da década de 80, outra corrente obteve destaque: a Geografia Humanista Cultural, com base na fenomenologia e no existencialismo. A prioridade das reflexões, então, passou a ser o sujeito e sua relação com o espaço, o qual é compreendido além da razão. Na Geografia Humanista, os conceitos de lugar e paisagem destacam-se a partir das vivências, da subjetividade e da identidade, tendo o ser humano como parte intrínseca da paisagem, e não apenas como observador. Em um contexto geral, a Geografia Humanística compreende as diversas paisagens a partir das percepções e do conjunto de valores e sentimentos correlacionados aos indivíduos (LOPES, 2010).

Diante da relevância e da contribuição de seus saberes, o currículo do ensino de Geografia na Educação Básica atende a diversos aspectos. Sendo assim, a Base Nacional Comum Curricular para o Mato Grosso (2018, p. 270) elucida:

[...] o componente curricular Geografia contribui de forma significativa no processo de ensino-aprendizagem dos estudantes, construindo de forma significativa as dimensões do currículo nos mais variados aspectos: sociais, políticos, culturais, éticos e econômicos, possibilitando o agir e pensar, ser e fazer na produção de saberes significativos que agregam conhecimentos de suma importância, contribuindo na formação social e na construção da autonomia para realização de uma leitura crítica da realidade e práticas sociais coerentes a tal.

Em vista disso, na sociedade contemporânea, na condição de dinâmica, globalizada e complexa, o ensino de Geografia torna-se uma valiosa ferramenta. Frise-se que, para a Educação Básica, é imprescindível, pois corresponde tanto aos saberes geográficos quanto aos pedagógicos, os quais norteiam a prática de ensino. Ainda, dispõe de relevância à elaboração 
de interpretações que vão auxiliar o educando no seu desenvolvimento ético e na participação cidadã na sociedade (MATO GROSSO, 2018).

\section{Percurso metodológico}

Para alcançar os objetivos propostos, o estudo foi baseado na pesquisa exploratória. Verificou-se que esse formato se coaduna com o objetivo de conhecer os fenômenos e fatos relacionados ao tema proposto. Quanto aos procedimentos de coleta de dados, utilizamos a pesquisa bibliográfica e a pesquisa de campo.

A pesquisa empírica foi realizada no espaço da escola estadual do munícipio de Vera MT, entre julho e novembro de 2018. Para a aplicação das entrevistas, seguiu-se um roteiro semiestruturado com a totalidade dos docentes atuantes no ensino de Geografia, neste caso, seis profissionais, após a aprovação dos colaboradores e da gestão da escola.

O roteiro foi composto por cinco questões geradoras direcionadas ao estudo em tela, quais sejam: 1- Como é trabalhar o ensino de Geografia na atualidade? 2-Você utiliza o livro didático em suas aulas? Qual é sua opinião sobre a utilização desse recurso nas aulas de Geografia? 3-Quais materiais, formas e instrumentos para o ensino de Geografia que você utiliza? 4- Qual é sua visão sobre trabalhar o ensino de Geografia correlacionando os conteúdos com a realidade local? 5- Existe, no seu local de trabalho, material suficiente para trabalhar sobre a realidade local? Os livros didáticos trazem conteúdos sobre a realidade regional ou local?

As entrevistas foram realizadas por meio de áudio e, posteriormente, transcritas. Após, foram agrupadas por tema questionado. Para garantir o anonimato, os sujeitos não foram identificados, para tanto, foram usadas a letra "D" (docente) e a numeração correspondente à ordem de pesquisa (ex.: D/01).

Concernente à abordagem, classifica-se como qualitativa, pois considera-se que responde a questões interpretativas, trabalhando com o universo de significados, motivos, aspirações, crenças, valores e atitudes, o que corresponde a um espaço profundo das relações, dos processos e dos fenômenos que não podem ser reduzidos à operacionalização de variáveis, cujo significado é o objetivo central da investigação (MINAYO, 1994).

A partir de uma leitura analítica realizou-se o estudo pormenorizado e a interpretação das informações coletadas, com a finalidade de ordenar e sumarizar as informações. As perguntas da entrevista foram agrupadas por semelhança e categorias para posterior análise, interpretação e construção do texto. Os dados obtidos obedeceram às fases de coleta de dados: 
“crítica dos dados; apuração dos dados: contagem e ordenação; exposição dos resultados: gráficos e tabelas; interpretação dos fatos" (ANDRADE, 2009, p.142).

\section{A DOCÊNCIA NO ENSINO DE GEOGRAFIA NA ATUALIDAdE E OS DESAFIOS: REFLEXÕES DOCENTES}

Para melhor fluidez do texto, as reflexões dos pesquisados foram dispostas em quadros, outras foram inseridas no corpo do texto, valendo-se como suporte e sustento às discussões e contextualizações, tendo em vista que, alguns assuntos que não faziam parte do roteiro inicial surgiram durante as entrevistas com alguns sujeitos. Sendo assim, o primeiro tema da pesquisa foi a respeito da docência na sociedade contemporânea. $\mathrm{O}$ objetivo foi verificar a natureza e as dificuldades correspondentes ao ensino da referida disciplina. Desse modo, a primeira indagação versou sobre como é o trabalho com o ensino de Geografia na atualidade (Quadro $1)$.

Quadro 1 - O ensino de Geografia na atualidade

\begin{tabular}{|c|c|}
\hline & Como é trabalhar o ensino de Geografia na atualidade? \\
\hline $\mathrm{D} / 01$ & $\begin{array}{l}\text { Percebo falta de interesse de alguns alunos. Também é difícil despertar o interesse deles quando } \\
\text { faltam recursos tecnológicos, computadores atualizados, mapas interativos e investimento em } \\
\text { projetos que viabilizem trabalhos de campo. As verbas governamentais estão muito irregulares nos } \\
\text { últimos anos, e isso faz com que os recursos necessários para a realização de projetos demorem. } \\
\text { Outra dificuldade que sinto é a formação continuada para os professores de geografia. Não há } \\
\text { formações voltadas para a área. Não temos nem liberdade e nem incentivo para participar de cursos e } \\
\text { palestras. Acaba ficando a cargo unicamente do próprio profissional buscar qualificação. Mas eu } \\
\text { tenho compromisso de trabalhar, lecionando geografia, mesmo diante das dificuldades! }\end{array}$ \\
\hline $\mathrm{D} / 02$ & $\begin{array}{l}\text { Trabalhar na área educacional independente da disciplina que está ministrando é um grande desafio, } \\
\text { pois a falta de interesse de muitos dificulta esse processo. O professor, no ensino de Geografia, } \\
\text { precisa não só motivar o aluno buscando novas informações, como também encontrar forças dentro } \\
\text { de si para enfrentar o dia a dia em sala de aula. Não são teorias mirabolantes, velhas e ultrapassadas } \\
\text { de autoritarismo que irão salvar a educação, pois o tempo mudou e novas ideias são necessárias para } \\
\text { superar o fracasso do sistema. Entendo que ser professor é um desafio, um fardo que a cada dia se } \\
\text { torna mais pesado e quase insustentável, porém a necessidade e o crédito de que a educação } \\
\text { transforma o mundo é o que fortalece o desejo de fazer a diferença em sala de aula. }\end{array}$ \\
\hline $\mathrm{D} / 03$ & $\begin{array}{l}\text { Muitas vezes faltam instrumentos e material adequado para as aulas, por exemplo: para confeccionar } \\
\text { um globo de isopor precisa de tintas, madeira, fios entre outros e acaba que o professor tem que arcar } \\
\text { com os custos dos materiais didáticos. Falta recurso para aula campo. Também há indisciplina dos } \\
\text { alunos. }\end{array}$ \\
\hline $\mathrm{D} / 04$ & $\begin{array}{l}\text { Faltam recursos financeiros para aulas de campo, para que nossos alunos possam conhecer o que eles } \\
\text { observam nos livros para que relacionem com a realidade. Faltam recursos tecnológicos e muitos } \\
\text { alunos não se interessam pelas aulas. }\end{array}$ \\
\hline $\mathrm{D} / 04$ & $\begin{array}{l}\text { A maior dificuldade que percebo é a estrutura do currículo ultrapassada e a falta de mais recursos } \\
\text { financeiros. }\end{array}$ \\
\hline $\mathrm{D} / 06$ & $\begin{array}{l}\text { Muitos estudantes pensam que a geografia é uma disciplina sem utilidade para o seu dia a dia. As } \\
\text { escolas não têm materiais que atraem os alunos, que empolguem e estimulem os alunos sobre a } \\
\text { disciplina. É claro que isso não é só culpa do governo, das escolas ou até mesmo dos professores, }\end{array}$ \\
\hline
\end{tabular}


mas sim também dos próprios alunos. Alguns não têm vontade para estudar. Estão na escola porque os pais obrigam, infelizmente.

Fonte: Elaborado pelos autores (2020).

Os docentes revelam preocupação com o desinteresse dos alunos aos estudos, aos conteúdos geográficos ou às aulas de Geografia. Inquietações já conhecidas ao se tratar da Educação Básica brasileira. Houve também menções a respeito da ausência de apoio ao docente, carência de investimento em recursos tecnológicos, falta de recursos para o desenvolvimento de aulas de campo e visitações, dadas como questões essenciais, assim como escassas formações continuadas para a área, dentre outras causas da desmotivação.

De acordo com o relato dos professores, trabalhar na educação está se tornando um desafio cotidiano. O educador percebe que necessita constantemente vivificar os alunos, mas ele também precisa ser motivado. A docência não é tarefa ordinária, pois, dentre diversas especificidades, o educador necessita de formação específica, conhecimento do conteúdo programado, entendimento da legislação de ensino, qualificação e aperfeiçoamento constante. Ainda, por que não dizer, afeição pelos alunos e pelo ato de educar, pois o tipo de relacionamento existente entre professor e aluno reflete no método do processo ensinoaprendizagem. Precisa ainda conhecer a realidade onde o aluno está inserido para dialogar sobre ela.

Sobre o desinteresse dos alunos aos conteúdos geográficos ministrados, Cavalcanti (2010) expõe que, para despertar o interesse cognitivo dos discentes, é necessário que o professor faça uma reflexão a respeito da contribuição do conhecimento geográfico para a vida cotidiana. Por essa razão, torna-se crucial refletir sobre o que é prioridade no ensino de Geografia em relação às suas bases fundamentais, observando que os alunos possuem um espaço-tempo a ser considerado. É necessário buscar o sentido real dos conteúdos estudados e, para tanto, o professor deve selecionar os temas a serem trabalhados, aproximando-os da realidade local dos discentes, fazendo interação com as questões globais. Deve, ainda, buscar explanar com clareza a importância desses saberes para suas vidas.

Landim Neto e Barbosa (2010) apontam que os alunos estão estafados de apenas ouvir os professores e fazer repetidas atividades metodicamente, sem um visível significado. $\mathrm{O}$ docente, portanto, tem como encargo auxiliar o estudante a filtrar e a interpretar a profusão de informações que ele recebe diariamente, na maioria das vezes, desconectadas.

Para os autores, alguns recursos podem ser utilizados na aprendizagem, tais como o uso de linguagem gráfica (gráficos, tabelas, croquis), linguagens cartográficas e cinematográficas, 
estudo do meio com trabalhos de campo, jogos pedagógicos, entre outros, que se assemelham às propostas de Cavalcanti (2010).

Os professores apresentaram queixas em relação à indisciplina e ao desinteresse pelos conteúdos escolares. Tal questão pode estar enquadrada como uma consequência das externalidades do ambiente escolar em que o estudante está inserido. Em muitas ocasiões, essas queixas são somente a ponta do iceberg dos vetores para a desmotivação dos alunos. O que acontece no ambiente escolar tem correspondência com a sociedade atual, que sofre com problemas complexos de ordem social, econômica e ambiental e relacional. Assim, problemas de relações sociais, alta desigualdade social, falta de perspectivas de trabalho, desequilíbrio emocional, entre outros, que constituem a realidade de muitas famílias brasileiras.

Partindo da premissa de que a escola é um microcosmo da sociedade, momento em que as crianças ampliam seu leque de relações, pois é o primeiro contato formal com a diversidade existente no mundo (fora do âmbito familiar), muitas das dificuldades sociais se manifestam em sala de aula. O professor, no entanto, pode auxiliar os alunos - seres em formação promovendo uma educação autônoma, crítica e reflexiva. Logo, é necessário trazer à tona a concepção de educação como um todo, conjugada a um projeto coletivo de escola, que envolva a comunidade educativa/aprendente na construção da igualdade e de condições dignas a todos.

Dando continuidade à investigação, o tema seguinte versou sobre os materiais, as formas e os instrumentos para o ensino de Geografia. Nesse ínterim, primeiramente, o objetivo foi compreender qual a visão dos professores acerca da utilização do livro didático em suas aulas, tendo em vista que é uma ferramenta comum na Educação Básica e, frequentemente, surge o questionamento sobre usá-lo ou não cotidianamente (Quadro 2).

Quadro 2 - Uso e opinião docente sobre o livro didático

\begin{tabular}{|c|c|}
\hline \begin{tabular}{|c|} 
Você utiliza o livro didático em suas aulas? Qual é sua opinião sobre a utilização desse recurso nas \\
aulas de Geografia?
\end{tabular} \\
\hline D/01 & $\begin{array}{l}\text { Utilizo o livro didático como um norte, porém, acrescento outros materiais complementando o } \\
\text { conteúdo, pois alguns materiais têm uma linguagem mais dinâmica. O livro é importante, porém } \\
\text { não é insubstituível. Estamos cada vez mais tendo que despertar a atenção de nossos alunos, assim } \\
\text { só o livro didático não contempla toda essa dinâmica. A junção do livro didático com as mídias } \\
\text { digitais proporcionará um aprendizado mais significativo. }\end{array}$ \\
\hline D/02 & $\begin{array}{l}\text { Acredito que o livro didático é de suma importância para o bom andamento e desenvolvimento das } \\
\text { aulas. Ele ajuda a esclarecer as aulas, uma vez que oferece diversos materiais como imagens e } \\
\text { mapas que são imprescindíveis; contudo, nem sempre são de melhor qualidade e, em alguns casos, } \\
\text { os livros escolhidos pelos professores não são os que a escola recebe. Porém, mesmo assim, são de } \\
\text { grande utilidade. }\end{array}$ \\
\hline D/03 & $\begin{array}{l}\text { Sim, dependendo da série/ano, eu uso. Porque quando o conteúdo é voltado para geografia física } \\
\text { fica mais fácil. Fica difícil trabalhar com o livro quando o conteúdo envolve geopolítica. O livro }\end{array}$ \\
\hline
\end{tabular}




\begin{tabular}{|c|c|}
\hline & $\begin{array}{l}\text { didático acaba se tornando ultrapassado pela dinâmica das transformações. E há livros também que } \\
\text { não trazem atividades diferenciadas. }\end{array}$ \\
\hline $\mathrm{D} / 04$ & $\begin{array}{l}\text { Sim, creio que é uma das ferramentas mais usadas, pois, com ele, consigo fazer com que os } \\
\text { estudantes acompanhem os conteúdos e as discussões. }\end{array}$ \\
\hline $\mathrm{D} / 05$ & $\begin{array}{l}\text { Sim, eu uso sempre, porque, na minha opinião, o livro didático é um guia para seguir o conteúdo. } \\
\text { Mas não quer dizer que precisamos seguir somente os livros. Nós podemos usar outras fontes de } \\
\text { informação. O livro é somente um dos elementos a trabalhar. }\end{array}$ \\
\hline D/06 & $\begin{array}{l}\text { Geralmente uso o livro didático para fazer o quadro dos conteúdos, mas busco artigos e textos } \\
\text { também em sítios de internet confiáveis. Eles nos auxiliam sempre, porém, em alguns casos, } \\
\text { dificultam para os professores se tomar por base apenas o livro. Mesmo assim, penso que é um } \\
\text { recurso necessário, e que é possível conciliar com outros instrumentos de apoio ao ensino. }\end{array}$ \\
\hline
\end{tabular}

Fonte: Elaborado pelos autores (2020).

Nesse contexto, pode-se observar que os docentes aprovam e utilizam o livro didático como ferramenta de trabalho, no entanto, questionam sua conexão com a realidade, bem como a desatualização de dados e conteúdos. Não raro, o livro didático é alvo de duras críticas, sobretudo sobre seu uso no contínuo nas aulas. No entanto, nesse cenário, Callai (2010) evidencia que o docente pode e deve utilizá-lo em suas aulas, tendo em vista que, em algumas ocasiões, esse será o único material acessível ao aluno, além disso, é uma poderosa ferramenta para a construção da cidadania. O professor, entretanto, precisa montar seu programa de ensino com coerência, sua escolha deve ser pertinente à realidade dos alunos. Dentre outras questões, ele deve examinar a veracidade dos conteúdos editados e sua devida atualização, pois, nos livros didáticos, estão dispostos vários dados de inúmeras fontes diferentes, bem como podem ser expostas realidades sociais, econômicas, políticas e, ainda, paisagens já transformadas, que necessitam de atualização.

Portanto, cabe ao docente problematizar e contextualizar o tema a ser trabalhado conjuntamente aos alunos, de modo que, a partir de seus saberes, expressem criticidade e autonomia. É interessante mencionar também que os conteúdos são sempre estabelecidos a partir de interesses de quem os elabora, ou seja, elencados de acordo com os interesses da sociedade atual, em sua forma e organização sócio-política-econômica hegemônica, cabendo ao professor orientar a devida análise, de modo que os discentes possam realizar estudos, debates e pesquisas, constituindo a possibilidade de questionamento e novas interpretações.

Nesse contexto, ressalta-se uma observação feita pelo docente D/02: “[...] em alguns casos, os livros escolhidos pelos professores não são os que a escola recebe.” Diante de tal declaração, parece claro que mesmo quando os professores desenvolvem uma avaliação sobre qual livro utilizarão com os alunos, mesmo quando podem avaliar a qualidade do material, bem 
como a coerência dos conteúdos e a atualização dos dados, entre outros itens, nada disso garante que o docente receba o livro selecionado por ele, pois nem sempre a rede estadual de ensino adota o livro solicitado pelos profissionais.

Além disso, é primordial que o educador tenha a clareza, no momento de selecionar o conteúdo de suas aulas, de que ele desempenha uma atividade de cunho social e de que desenvolve metodologicamente o ensino. Sob esse aspecto, o livro didático é um valioso instrumento de conhecimento produzido. Apesar disso, não se pode aceitá-lo como inquestionável e absoluto, ou mesmo como único recurso, como se o ensino de Geografia começasse e findasse ali - conforme foi observado em várias falas. "Se o professor não consegue ser o condutor de sua aula - seja por falta de conhecimento específico da matéria, seja por falta de outras condições, alguém externo ocupa o seu lugar" (CALLAI, 2010, p. 139).

O processo de ensino-aprendizagem não pode ser mecânico, estático; o ensino de Geografia, tanto na Educação Básica quanto na formação universitária, precisa atualizar-se constantemente e reduzir a distância que há entre essas instâncias. Conforme Martins (2015), o professor, para atuar no ensino de Geografia, precisa ter autonomia e precisa ser capaz de resolver os desafios correspondentes à atividade docente. A liberdade faz o docente pensar sua prática, tomar decisões, questionar suas ações e reorganizar seus planejamentos. O professor exercita sua cidadania quando se torna capaz de gerar sua própria atividade profissional: "Ser professor de Geografia exige domínio de informações e de referências pedagógicas, ou seja, competência profissional" (CALLAI, 1995, p. 4).

Importante destacar que, durante as entrevistas, conforme os entrevistados expunham sobre a utilização do livro didático, também evidenciaram que, além desse material, utilizavam outros recursos para desenvolver o ensino de Geografia, tais como documentários, filmes, letras de músicas, poemas, textos extraídos de outros livros, internet, entre outros exemplos, já respondendo à questão apresentada abaixo (Quadro 3).

Quadro 3 - Práticas e Metodologias de ensino de Geografia

\begin{tabular}{|c|l|}
\hline \multicolumn{2}{|c|}{ Quais materiais, formas e instrumentos para o ensino de Geografia que você utiliza? } \\
\hline D/01 & $\begin{array}{l}\text { Eu utilizo bastante as mídias digitais (celulares, internet, computadores). Tudo o que consigo trazer } \\
\text { de forma agradável eu reorganizo, como mapas ampliados. Utilizo tinta e argila para moldar } \\
\text { materiais como relevo. Estes são alguns exemplos que acredito que despertam a atenção dos alunos, } \\
\text { mas não são todos os conteúdos que consigo trabalhar assim. O retorno é positivo. }\end{array}$ \\
\hline D/02 & $\begin{array}{l}\text { Utilizo nas minhas metodologias, quando possível, aulas de campo, mapas específicos e, } \\
\text { dependendo da aula, quadro, projetor, músicas, poesias, livro didático, livros complementares. }\end{array}$ \\
\hline D/03 & $\begin{array}{l}\text { Costumo utilizar bastante o computador, projetor, mapas, aula de campo, confecção de cartazes, } \\
\text { roda de conversa, debates, seminário, música, poemas. Gosto muito de trabalhar com letras de }\end{array}$ \\
\hline
\end{tabular}




\begin{tabular}{|c|l|}
\hline & $\begin{array}{l}\text { música, pois os adolescentes gostam e através da letra das músicas podemos despertar um } \\
\text { pensamento crítico. }\end{array}$ \\
\hline D/04 & $\begin{array}{l}\text { A disciplina de Geografia permite o uso de uma diversidade enorme de matérias multimídia como } \\
\text { filmes ou documentários, bem como imagens ou até mesmo música. Sendo assim, procuro usar de } \\
\text { tudo um pouco para a melhor compreensão do conteúdo. }\end{array}$ \\
\hline D/05 & $\begin{array}{l}\text { Tento utilizar de tudo um pouco do que tenho disponível. Projetor, lousa digital, quadro branco, } \\
\text { livro didático, globo, mapas, entre outros materiais paradidáticos que combinem com o tema. As } \\
\text { aulas seguem a forma expositiva-dialogada. }\end{array}$ \\
\hline D/06 & $\begin{array}{l}\text { Além do livro didático, procuro trabalhar bastante com os recursos da internet, com textos extras, } \\
\text { vídeos, documentários, filmes, letras de música, utilizando o projetor de multimídia e, quando } \\
\text { possível, faço aula de campo. }\end{array}$ \\
\hline
\end{tabular}

Fonte: Elaborado pelos autores (2020).

A atuação dos professores, segundo seus relatos, vai ao encontro do que Cavalcanti (2010) evidencia como práticas docentes valorosas, pois, segundo a autora, os recursos didáticos necessitam ir além do uso do livro didático e das tradicionais aulas expositivas, outras linguagens alternativas podem ser utilizadas no ensino-aprendizagem à análise geográfica: filmes, documentários, músicas, fotografias, literatura, texto jornalístico, teatro, charge, jogos virtuais, imagens diversas, incluindo as de geoprocessamento (de satélite), programas de televisão, entre outros recursos. Levando-se em consideração, também, que os estudantes estão envoltos em um mundo dinâmico, repleto de inovações e informações, são necessárias também inovações no processo de ensino-aprendizagem.

Conforme Pérez Goméz (1998), atualmente, a escola perdeu sua supremacia na transmissão de informações para os meios de comunicação de massa, principalmente para a televisão e, na atualidade, para a internet, com a conexão de computadores, notebooks, tablets e aparelhos móveis de comunicação, como celular, que possuem um conjunto de aplicativos. Esses dispositivos oferecem diversidade de programações, informações e conteúdo. Esse cardápio multivariado - de opções culturais ou não - adentra a vida das pessoas e colabora para a formação cognitivo-geográfica das crianças e jovens, que vão criando concepções ideológicas, as quais podem ser utilizadas para explicar e interpretar a realidade. Assim, os alunos já chegam à escola com acúmulo de conhecimento e concepções que devem ser reinterpretadas no ensino geográfico.

Sabe-se que, toda essa rede de informações e o mundo das relações sociais que rodeiam o discente apenas cumprem a função de reprodução da cultura dominante e não a reelaboração crítica e reflexiva. O objetivo das organizações sociais, políticas e econômicas é a persuasão do indivíduo; todavia, a reflexão racional e a comparação crítica de concepções podem ser realizadas na escola no contexto da socialização contemporânea (PÉREZ GOMÉZ, 1998). 
Neste sentido, Celeri, Lima e Oliveira (2017) apontam que um dos grandes problemas do ensino de Geografia está na formação do professor, pois ele necessita aprimorar os conhecimentos geográficos, apropriar-se dos fundamentos teóricos da disciplina, ou seja, tem que conhecer a ciência geográfica, sua trajetória, e saber ensiná-la. No entanto, a grande reclamação dos docentes é a falta de apoio didático, a falta de capacitação na área em que atuam e a falta de formação continuada, conforme observa o professor "D/01", no Quadro (1).

Em contrapartida, Callai (1995) expõe que a atualização é uma condição necessária para o exercício de qualquer profissão. Sendo assim, o professor precisa repensar as suas práticas e pesquisar continuamente a respeito de metodologias de ensino, adequando-se às mudanças tecnológicas, socioespaciais e econômicas, objetivando a incorporação de elementos da realidade que são relevantes aos próprios alunos.

$\mathrm{Na}$ investigação, um dos problemas encontrados foi a falta de formação profissional correspondente à disciplina de regência do professor. A escola possui metade dos professores atuantes no ensino em Geografia com formação específica de licenciatura na área, ou seja, três docentes. Na escola mencionada, sobre outros docentes que ministram a disciplina de Geografia, dois são graduados em outras áreas, como História e Ciências Biológicas.

Ressalta-se que a situação exposta não é exclusiva da escola na qual foi realizada a pesquisa, assim, tal questão pode ser uma das razões da ausência de um ensino de Geografia mais significativo. Landim Neto e Barbosa (2010) constataram, em um estudo semelhante, que a falta de habilitação adequada ou a ausência de uma formação básica em Geografia pode ampliar os problemas de ensino-aprendizagem e de comportamento na referida disciplina.

Diante dessa situação, Cacete (2004), em um estudo sobre a formação do professor de Geografia, destaca que está ocorrendo uma contínua redução na oferta e demanda de cursos de graduação voltados para as licenciaturas, incluindo Geografia, que são substituídos por outros voltados a carreiras de maior prestígio e maior retorno financeiro. As graduações em licenciatura são oferecidas primordialmente nas instituições privadas que oferecem ensino precário e superficial; no entanto, o desprestígio histórico da profissão docente, somado às novas exigências do mercado de trabalho, corroboram para uma crise quanto à procura por esses cursos e, como consequência, estão se formando menos professores do que realmente se necessita (CACETE, 2004), além de os licenciados na área buscarem outras atividades profissionais de maior retorno financeiro.

Muitas são as formas e metodologias que podem colaborar com a construção do conhecimento geográfico, entretanto, neste artigo, optamos por fazer uma análise da percepção 
dos professores sobre a importância na correlação dos conceitos e conteúdos geográficos com o cotidiano dos alunos. Entendemos que, ao proporcionar o estudo das implicações e particularidades locais, como no caso do município de Vera, há a possibilidade de oportunizar o conhecimento dos fatos históricos-geográficos do qual participam e participaram seus pais. Sendo assim, permite-se o entendimento dos fenômenos que ocorreram e a materialidade dos acontecimentos, oportunizando que o aluno resgate a história de sua própria vida e tenha elementos de compreensão da sua realidade. Assim, foi questionado sobre o trabalho com o ensino de Geografia correlacionado à realidade local, nesse aspecto, verificou-se a visão deles em relação à importância da Geografia local para a compreensão de mundo (Quadro 4).

Quadro 4 - Percepção sobre o ensino de geografia e a realidade local

\begin{tabular}{|c|c|}
\hline \multicolumn{2}{|r|}{$\begin{array}{l}\text { Qual é sua visão sobre trabalhar o ensino de Geografia correlacionando os conteúdos com a realidade } \\
\text { local? }\end{array}$} \\
\hline $\mathrm{D} / 01$ & $\begin{array}{l}\text { Eu acredito que não adianta eu trabalhar a realidade dos Estados Unidos ou da Rússia se eu tenho } \\
\text { muitas coisas aqui parecidas. Não temos o frio, mas temos as pessoas que passam fome, sem } \\
\text { emprego. Temos que falar para os alunos sobre os tipos de plantações, mas temos que trazer para a } \\
\text { nossa realidade, local que é cercado de extensas plantações de soja. Por exemplo, se os terrenos não } \\
\text { fossem planos como em nosso município, seria impossível desenvolver uma agricultura altamente } \\
\text { mecanizada. Essa agricultura, com a mecanização, exclui mão de obra. Assim, se eles não } \\
\text { conhecem a sua realidade, o que podem fazer? Portanto, primeiro, tenho que conhecer a cidade, o } \\
\text { município, a região, para depois conhecer a realidade de outros lugares. }\end{array}$ \\
\hline $\mathrm{D} / 02$ & $\begin{array}{l}\text { Eu penso que conhecer o lugar que você mora, conhecer a realidade que você vive é muito } \\
\text { importante. Eu acredito que é muito importante que eles façam pesquisa sobre onde vivem. Os } \\
\text { estudantes têm que conhecer primeiro onde vivem para depois conhecer a realidade de outros } \\
\text { países, e saber como a nossa realidade vai interferir em outro local, e como a dos outros interfere na } \\
\text { nossa. Essa é a ponte do conhecimento. }\end{array}$ \\
\hline $\mathrm{D} / 03$ & $\begin{array}{l}\text { Estudar a realidade local é de suma importância, porque nós estamos no centro de um grande } \\
\text { problema ambiental. A Amazônia vem sofrendo uma mudança catastrófica, destruída pela inserção } \\
\text { de lavouras e pecuária. Nós temos a maior floresta do mundo e é aqui que está acontecendo essa } \\
\text { grande transformação, essa destruição toda. Nosso estudo em Geografia tem o dever de mostrar e } \\
\text { debater o que está acontecendo em nossa realidade, em nosso entorno. }\end{array}$ \\
\hline $\mathrm{D} / 04$ & $\begin{array}{l}\text { Penso ser essencial a nós educadores. Se não relacionar o conteúdo com a realidade local não vale a } \\
\text { pena ensinar o que se passou e por que ocorreu. Temos isso tanto nos conteúdos de Geografia } \\
\text { Física como Humana, todos os conteúdos temos que trazer para realidade vivida. }\end{array}$ \\
\hline $\mathrm{D} / 05$ & $\begin{array}{l}\text { É muito importante relacionar os conteúdos com a realidade local, pois os alunos se deparam com o } \\
\text { que acontece na nossa região. Então é bom trazer os conteúdos e relacionar o saber sobre o global } \\
\text { com o nosso local, pois interagem. O comércio da produção local de soja vai para a China, por } \\
\text { exemplo. O modo de produção local afeta nossa organização de sociedade, assim como a } \\
\text { urbanização do mundo nos afeta. }\end{array}$ \\
\hline $\mathrm{D} / 06$ & $\begin{array}{l}\text { Eu costumo dizer para os meus alunos, "quando eles terminam o ensino médio, eles precisam, são } \\
\text { obrigados a saber as condições ambientais de onde eles vivem, a questão climática, as questões } \\
\text { sociais, econômicas". }\end{array}$ \\
\hline
\end{tabular}

Fonte: Elaborado pelos autores (2020). 
$\mathrm{Na}$ fala dos docentes, fica visível a percepção a respeito da importância de trabalhar a Geografia local, conhecer o espaço de vivência, os problemas, partindo da escala local para a global, em uma espécie de ir e vir dialógico. Em muitas situações, os livros didáticos não trazem dados sobre o local de vivência dos alunos. É importante, por isso, que os alunos entendam que seu espaço de vivência não está isolado, está correlacionado com decisões e processos externos, e o professor pode orientar a esse processo de construção do conhecimento. Como expôs o professor D/02: "De que adianta os alunos saberem as razões da independência dos Estados Unidos se eles não conhecem sequer os problemas de onde moram e que eles mesmos passam?"

A necessidade do saber local não significa, entretanto, que as questões globais ou sobre outras realidades devem ficar de lado, porque, partindo de experiências externas, suscitam-se reflexões sobre o contexto local. Há de se fazer um comparativo: se em outros países houve/há problemas de desigualdade social, como em nosso país, em nosso estado ou município ela se apresenta? Quando se trata de propriedades latifundiárias, por exemplo, é possível discutir a geografia agrária especificando que, no caso do município estudado, os proprietários latifundiários são sulistas, descendentes de europeus que adotaram os modelos vigentes em seus países de origem. Em um assentamento rural, ou na periferia da cidade, a situação mostra outra face da realidade: ali estão os descendentes de povos africanos que foram escravizados e posteriormente largados à própria sorte, em luta por terra, trabalho, renda, respeito e dignidade.

É necessário e importante reconhecer as correlações das espacialidades dos estudantes, fazer a conexão com o currículo escolar, com o conteúdo abordado nas aulas de Geografia, com o cotidiano da sala de aula e do espaço escolar como um todo. Sendo assim, os fatos devem ser tratados a partir da realidade do educando, o que possibilita maior identificação com o conteúdo trabalhado, porque os alunos precisam se perceber como sujeitos do processo a partir do estudo do seu lugar (CAVALCANTI, 2010).

Nesse viés, os discentes precisam se perceber como agentes sociais, que fazem parte do processo. Uma situação típica, que pode servir de exemplo, é a discussão acerca da importância da Amazônia e de sua degradação. Poucos alunos, no entanto, conseguem perceber que o município de Vera está inserido na Bacia Amazônica, no Bioma Amazônia (em sua porção maior), na Amazônia Legal, e que as ações humanas podem colaborar com a preservação ou com a destruição do meio ambiente e que terão consequências na realidade local, mas também planetária. Portanto, como afirma Cavalcanti (2010), é papel da Geografia desenvolver o pensamento conceitual que permite mudanças na relação do sujeito com o mundo. 
Entretanto, os professores participantes de estudo deixaram explícito o fato de que, para lecionar sobre as questões mais próximas ou sobre as particularidades locais, precisam buscar informações adicionais para anexá-las aos demais componentes do currículo da disciplina. Também, do mesmo modo, para realizar atividades interdisciplinares com as áreas afins, junto aos colegas docentes, devido à ausência de material e formação acerca da realidade local.

Acrescenta-se, ainda, nesse contexto, que um ensino intertextual é necessário, tendo em vista a imprescindibilidade de evidenciar particularidades e as implicações econômicas e socioambientais da região Centro-oeste e do Mato Grosso, uma vez que os materiais fornecidos pelos órgãos governamentais não trazem. As reflexões dos professores no quadro (5) a seguir são elucidativas:

Quadro 5 -Material didático sobre a realidade local

\begin{tabular}{|c|l|}
\hline \multicolumn{2}{|c|}{$\begin{array}{c}\text { Existe, no seu local de trabalho, material suficiente para trabalhar sobre a realidade local? Os livros } \\
\text { didáticos trazem conteúdos sobre a realidade regional ou local? }\end{array}$} \\
\hline D/01 & $\begin{array}{l}\text { Não, de forma alguma. Durante a aula, precisa fazer essa abordagem porque o livro didático não } \\
\text { faz. Temos de buscar material porque nos livros didáticos não há. }\end{array}$ \\
\hline D/02 & $\begin{array}{l}\text { Não há materiais, e o livro didático não traz nada sobre a realidade local, especificamente, sempre } \\
\text { ocorre a necessidade de contextualizar. }\end{array}$ \\
\hline D/03 & $\begin{array}{l}\text { Não! Infelizmente, os livros didáticos abordam uma realidade nacional ou estadual, nem dá para se } \\
\text { dizer que é uma realidade regional. O livro didático é carente de informações e estudos sobre o } \\
\text { nosso estado e nossa região. É muito superficial. }\end{array}$ \\
\hline D/05 & $\begin{array}{l}\text { Não, infelizmente os nossos livros vêm sempre com dados atrasados e até fotos também, isso eu } \\
\text { sempre notei, mesmo com a tecnologia, ainda aparecem dados atrasados uns 3 ou 4 anos, pois não } \\
\text { são feitas as revisões anuais. }\end{array}$ \\
\hline $\begin{array}{l}\text { Na verdade, nossos livros não tratam a realidade da nossa região. A única coisa a fazer é ler e tirar } \\
\text { os dados e aí embasar, mas, na verdade, não vem nenhum material propício para manusear sobre a } \\
\text { nossa região, nem mesmo mapas e conteúdo para trabalhar. }\end{array}$ \\
\hline $\begin{array}{l}\text { Não existe material suficiente sobre a realidade local. Eu penso que são muito pobres em relação a } \\
\text { esse assunto. São superficiais. Então eu acredito que os livros que vêm para nós trabalharmos estão } \\
\text { longe do contexto local, da nossa realidade. Penso que para trabalharmos esse assunto do contexto } \\
\text { local temos de sair para pesquisar realmente com os alunos, fazer aulas de campo, estudos e } \\
\text { debates. }\end{array}$ \\
\hline
\end{tabular}

Fonte: Elaborado pelos autores (2020).

De acordo com os professores, nos livros didáticos disponibilizados pelo Ministério da Educação, para a Educação Básica, são escassos os dados e conteúdos referentes à região Centro-Oeste, ao Mato Grosso e, principalmente, a respeito do norte de Mato Grosso, e mesmo da realidade local. Essa lacuna de conhecimento geográfico exige que o professor procure, em outras fontes, materiais que ilustrem a Geografia local, trazendo, para suas aulas, debates que correlacionem o global com o local. Ocorre que, se o professor não tiver sido preparado na universidade para essa forma de trabalho, a lacuna irá persistir e o ensino ficará superficial e 
descontextualizado, por vezes sem sentido aos discentes. Daí a importância de uma formação que possibilite ao docente uma autonomia construtiva de conhecimento sobre a realidade local, realizando interações com a comunidade, fazendo palestras, seminários e atividades a campo.

No estado de Mato Grosso, a Base Nacional Comum Curricular estabelece vários objetivos direcionados ao componente "Geografia" que devem ser cumpridos nos anos finais no Ensino Fundamental:

- Analisar o meio ambiente do estado de Mato Grosso, correlacionando as diferentes escalas e diversos aspectos (físicos, sociais, econômicos, culturais e ambientais);

- Reconhecer e identificar as paisagens do território mato-grossense e suas interações com diferentes escalas no espaço geográfico, propiciando a valorização do patrimônio sociocultural e ambiental, ressignificando sua identidade;

- Analisar o espaço geográfico como um processo de construção das relações entre os seres humanos, e destes com a natureza, estabelecendo conexões entre o espaço geográfico mato-grossense e outros espaços;

- Construir e compreender o conceito de território, caracterizando as formas de apropriação dos territórios no estado de Mato Grosso (MATO GROSSO, 2018, p. 275).

Todavia, de acordo com os professores, até o momento da pesquisa, não havia material didático-pedagógico adequado para trabalhar com os alunos que trouxessem elementos direcionados à Geografia do Mato Grosso, assim como não houve menção da disponibilização de apoio para cumprir esses objetivos propostos. Diante disso, fica um questionamento: é o professor que deve providenciar esses materiais? Elaborar tais materiais seria uma responsabilidade docente? Quais são as condições oferecidas para tal tarefa? Além disso, sequer formação continuada direcionada à área, até o momento da pesquisa, havia sido oferecida aos educadores.

É de alta relevância o suporte para os docentes cumprirem os objetivos propostos, pois trabalhar o espaço de vivência é questão indispensável, conhecer a história e a geografia do seu local, as rugosidades, os fatos históricos, as lutas de classes, por terra e territórios. Entender qual é a correlação do seu espaço, do seu "mundo" com o mundo "lá fora", compreender por que algumas situações que ocorrem em outros países repercutem no seu espaço de vivência como, por exemplo: - Por que no território do município se produz grande quantidade de soja e de milho, que são commodities de exportação para a Europa, Japão e China, e não são produzidos outros alimentos à sociedade local, sendo necessário adquirir frutas e verduras de outras regiões ou de outros países? A diversificação da produção não poderia impulsionar a economia local gerando trabalho e renda, mantendo a população no próprio município? 
Além de cumprir os objetivos propostos para Educação Básica, o professor de Geografia, ao trabalhar com os alunos as particularidades do espaço de vivência, está possibilitando-lhes uma educação para a cidadania. E, para tanto, deve-se considerar a análise do poder da transformação, levando em conta as contradições, disfunções e tensões nas instituições sociais (escola, família, etc.) nas quais o estudante vive (CALLAI, 2001).

Para mudar a realidade na qual está inserido, não basta apenas o estudante conhecer as particularidades, as organizações sociais e estruturais do seu espaço de vivência. É necessário o conhecimento que proporcione o questionamento dos fatos, a análise das situações, para exercer efetivamente a cidadania com consciência de seus direitos e responsabilidades, como ser autônomo, mas pertencente a uma coletividade, a uma sociedade. Assim sendo, o ensino de Geografia deve se apresentar e contribuir com essa formação cidadã.

Para tanto, é primordial proporcionar aos discentes o conhecimento do seu local e de sua história, sem deixar de olhar para além dos limites do seu município, considerando que o que ocorre nele é resultado de dinâmicas exteriores (CALLAI, 2001). Assim, o ensino deve estar voltado do local para o global ou vice-versa, dependendo do conteúdo abordado e da necessidade do estabelecimento da relação desses dois níveis geográficos, para a interpretação de determinado fenômeno ou processo.

\section{CONSIDERAÇÕES FINAIS}

$\mathrm{Na}$ atualidade, ensinar Geografia pode ser considerado uma tarefa desafiadora, como expuseram os entrevistados. Cada vez mais, cresce a exigência ao docente, como conhecer os fundamentos teóricos da disciplina, sua trajetória e as práticas de ensino possíveis. Desse modo, o professor tem a incumbência de estar sempre atento, pois deve abordar os conceitos de uma forma compreensível ao aluno. Em outros termos, o estudante deve entender seu espaço de vivência e poder atuar nele com autonomia e consciência cidadã, uma vez que ele próprio é um ser histórico e está contextualizado em um espaço geográfico e, ainda, é dotado de saberes que devem ser considerados pelo professor.

Nos apontamentos docentes, fica exposta a falta de interesse dos alunos pela disciplina e, ao mesmo tempo, não é dado à docência o apoio necessário para facilitar o desenvolvimento de aulas mais instigantes, que despertem a busca de conhecimentos referentes à realidade local pelos discentes. Ainda, faltam recursos tecnológicos, destinação de recursos financeiros para a confecção de materiais pedagógicos e sua testagem no processo de aprendizagem, assim como 
para a realização de aulas de campo, visitações, dentre outras atividades importantes ao aprendizado.

Certamente, a falta de apoio é um complicador para o processo de ensino-aprendizagem; mas, além disso, a formação (ou a falta dela) também pode contribuir para a ineficiência desse processo, inclusive para o desinteresse dos alunos. Nos casos em que o docente não domina os conteúdos da disciplina e as metodologias de ensino, por óbvio, não consegue desenvolver abordagem capaz de facilitar o aprendizado e de torná-lo significativo para a vida do estudante, razão pela qual apontam (os entrevistados) a necessidade da formação continuada e a qualificação docente.

Nesse cenário, quando o aluno compreende os fatos e fenômenos contidos no espaço vivido, ele deixa o senso comum e tende a pensar, a refletir sobre as feições espaciais moldadas de sua realidade. Assim, tão importante quanto a compreensão das relações, da história e configuração espacial de seu lugar, é saber que nada é isolado, atemporal, pois faz parte de um todo e responde a anseios e estímulos internos e externos, recebendo interferência sociopolítica e econômica sobre a construção do espaço e a dinâmica territorial. Do mesmo modo, ações locais podem ter repercussão e consequência universal em maior ou menor grau.

Por fim, essencial sublinhar que a Geografia é um componente curricular de suma importância para a compreensão da sociedade e do mundo, visto que pode instrumentalizar para a transformação da realidade. Logo, tais aspectos devem ser trabalhados de forma interdisciplinar e colaborativa com outras áreas do saber, objetivando-se, assim, a produção do conhecimento e a interpretação da realidade tanto dos docentes como dos discentes.

O processo de ensino-aprendizagem precisa ser dinâmico e ativo, por isso, pesquisas que buscam compreender os saberes e as práticas docentes a partir do que ocorre na sala de aula, bem como indicar renovações nas metodologias de ensino, devem ser incentivadas no meio acadêmico e nas escolas, de maneira interativa, na intenção de reduzir as distâncias entre esses dois espaços constituintes do processo educativo.

\section{REFERÊNCIAS}

ANDRADE, Maria Margarida de. Introdução à metodologia do trabalho científico. 9. ed. São Paulo: Altas, 2009.

CACETE, Núria Hanglei. A formação do professor de Geografia: uma questão institucional. Boletim Goiano de Geografia, Goiânia, v. 24, n. 1-2, p.23-30, jan./dez. 2004. Disponível em: https://www.revistas.ufg.br/bgg/article/view/4130/3633. Acesso em: 25 abr. 2019. 
CALLAI, Helena Copetti. A formação do professor de Geografia. Boletim Gaúcho de Geografia, Porto Alegre, n. 20, p.38-41, dez. 1995. Disponível em:

https://seer.ufrgs.br/bgg/article/view/38032/24535. Acesso em: 20 mai. 2019.

CALLAI, Helena Copetti. A Geografia e a escola: muda a Geografia? Muda o ensino? Terra Livre, v. 1, n. 16, p. 133-152, 2001. Disponível em:

http://agb.org.br/publicacoes/index.php/terralivre/article/viewFile/353/335. Acesso em: 12 jun. 2019.

CALLAI, Helena Copetti. A Geografia escolar e os conteúdos da Geografia. Anekumene, n. 1, p. 128-139, 2010.

CAVALCANTI, Lana de Souza. A Geografia e a realidade escolar contemporânea: avanços, caminhos, alternativas. I SEMINÁRIO NACIONAL: CURRÍCULO EM MOVIMENTOPERSPECTIVAS ATUAIS. Belo Horizonte. Anais... p. 1-13, 2010. Disponível em: http://portal.mec.gov.br/docman/dezembro-2010-pdf/7167-3-3-geografia-realidade-escolarlana-souza/file. Acesso em: 20 mar. 2019.

CELERI, Marcio José; LIMA, Roberta Maria Batista de Figueiredo; OLIVEIRA, Josenira Ferreira de. Textos e contextos do ensino da Geografia no ensino fundamental na escola municipal Presidente Costa e Silva, Maranhão, Brasil. Espacios. v. 38, n. 30, p.6-21, mar. 2017. Disponível em: https://www.revistaespacios.com/a17v38n30/a17v38n30p06.pdf. Acesso em: 23 nov. 2019.

DA SILVA, Renata Maria; BAMPI, Aumeri Carlos. Entre a motivação e a precariedade: a situação camponesa no processo inicial da colonização na gleba celeste, Vera, MT.

PEGADA-A Revista da Geografia do Trabalho, v. 21, n. 1, p. 169-192, 2020. Disponível em: https://revista.fct.unesp.br/index.php/pegada/article/view/7056/pdf. Acesso em: 10 jun. 2020.

FERNANDES, Maria José da Silva. A Geografia como disciplina escolar: breve trajetória. In. Ambiente Virtual de Aprendizagem (AVA). EaD PMB. Aprendizado Inteligente. 2012. Bauru. SP.

KOHLER, Marisa Regina; BAMPI, Aumeri Carlos; SILVA, Carlos Alberto Franco da. A problemática socioambiental da expansão da fronteira em Vera (MT), Papers do NAEA, Universidade Federal do Pará, 2017.

LANDIM NETO, Francisco Otávio; BARBOSA, Maria Edivani Silva. O ensino de Geografia na educação básica: uma análise da relação entre a formação do docente e sua atuação na Geografia escolar. Geosaberes: Revista de Estudos Geoeducacionais, v. 1, n. 2, p. 160-179, 2010. Disponível em: http://www.geosaberes.ufc.br/geosaberes/article/view/44/68. Acesso em: 19 set. 2019.

LOPES, Jecson Girão. A Geografia humanística como ferramenta de ensino. Geosaberes: Revista de Estudos Geoeducacionais, Ceará, v. 1, n. 2, p.26-38, dez. 2010.

MARTINS, Rosa Elisabete Militz. A formação do professor de Geografia: aprendendo a ser professor. Geosul, Florianópolis, v. 60, n. 30, p.249-265, dez. 2015. Disponível em: http://www.geosaberes.ufc.br/geosaberes/article/view/51/59. Acesso em: 15 ago. 2019. 
MATO GROSSO. Documento de referências curricular para Mato Grosso. Ensino Fundamental Anos Finais. 2018. Cuiabá, MT. Disponível em: <https://drive.google.com/file/ d/1sW32tgc-y5O0_8QMbcB87hSrTpoA8XID/view>. Acesso em: 25 jan. 2020.

MELO, Adriany de Ávila; VLACH, Vânia Rúbia Farias; SAMPAIO, Antônio Carlos Freire. História da Geografia escolar brasileira: continuando a discussão. VI CONGRESSO LUSOBRASILEIRO DE HISTÓRIA DA EDUCAÇÃO, Uberlândia, MG. Anais... abr. 2006.

MINAYO, Maria Cecília de Souza. Pesquisa social: teoria, método e criatividade. 6. ed. Petrópolis: Vozes, 1994.

OLIVEIRA, Ariovaldo Umbelino de. Educação e ensino de Geografia na realidade brasileira. In: OLIVEIRA, A. U. Para onde vai o ensino de Geografia. São Paulo: Contexto, 1989. p. $135-144$

PÉREZ GÓMEZ, Angel Ignácio. As funções sociais da escola da reprodução à reconstrução crítica do conhecimento e da experiência. In: SACRISTÁN, J. G.; PÉREZ GÓMEZ, A. Compreender e transformar e ensino. 4. ed. Porto Alegre: Artmed, 1998. p. 13-26.

ROCHA, Genylton Odilon Rego da. A trajetória da disciplina Geografia no currículo escolar brasileiro (1837-1942). 1996. 300 f. São Paulo. Dissertação (Mestrado em Educação) - Programa de Estudos Pós-Graduados em Educação: Currículo. Pontifícia Universidade Católica de São Paulo (PUCSP), São Paulo, SP, 1996. Disponível em: <https://tede2.pucsp.br/handle/handle/9603>. Acesso em: 10 nov. 2019.

Recebido em: 24 de junho de 2020.

Aprovado em: 26 de agosto de 2020. 